Article

\title{
Experience is Key: Examining the Relative Importance of Factors Influencing Individuals' Water Conservation
}

\author{
Derrick Holland ${ }^{1, *}$, Kristina Janét ${ }^{2}$ and Asheley Landrum ${ }^{2}$ \\ 1 Advertising and Public Relations, College of Communication and Information, University of Tennessee, \\ Knoxville, TN 37996, USA \\ 2 Public Relations and Advertising, College of Media and Communication, Texas Tech University, \\ 2500 Broadway, Lubbock, TX 79409, USA \\ * Correspondence: dholla20@utk.edu; Tel.: +1-512-739-6815
}

Received: 30 July 2019; Accepted: 5 September 2019; Published: 9 September 2019

\begin{abstract}
Conservation of our global natural resources is one of the most pressing concerns facing our international society. One of these crucial resources is water. The current study sought to understand how individual factors such as experience with water scarcity, message framing, and ideology can impact perceptions, attitudes, and behaviors related to water conservation. Through the utilization of an online experiment, the current findings suggest that higher levels of experience with water scarcity predict more concern, more positive credibility perceptions of water conservation messages, and a higher likelihood of conserving water in the future. Message framing, specifically gain frames, predicted more concern and more positive perceptions of message credibility, and ideology only predicted perceptions of message credibility. Implications for global communities, resource managers, and policy decision-makers are discussed.
\end{abstract}

Keywords: water conservation; natural resources; social science; experience; experiment

\section{Introduction}

Water is a precious global resource, which in turn makes its conservation essential. There are many techniques for the preservation of water, but arguably the most important strategy is to impact and shape the public policy surrounding the conservation. Creating and developing the water public policy involves many different steps, including understanding issues such as conservation, pollution, and management. Apart from simply understanding these issues, the public policy can rarely be implemented without gauging and shaping the attitudes, perceptions, and behaviors of those who would be impacted by the said policy. Thus, for public policy makers and conservation managers to successfully shape water legislation, they must have a firm grasp of how members of the public view and react to issues surrounding water conservation.

Although the availability of water across the globe depends on a variety of factors, such as global temperatures, agricultural practices, and residential water usage, the practice of engaging in water conservation efforts also depends on individual-level factors, such as personal experience and worldviews [1]. Based on these assumptions, resource managers, public policy makers, and social scientists are exploring individual characteristics that may help to predict the pro-water conservation behavior. Additionally, researchers and communication practitioners have also grown increasingly interested in what types of messages interact with these individual characteristics to result in a higher likelihood of water conservation in residential areas. Although research surrounding these details is budding in the social science arena, there remains a lack of theoretical and practical research that resource managers and policy makers can implement to safeguard our residential water resources. 
Safeguarding these resources can include improving perceptions of the content regarding water scarcity, and more importantly, increasing the likelihood to conserve water. The current study seeks to fill this gap.

Although reporting social science results as tangible or in the form of an activity that everyday people can participate in has been identified as a successful game plan in the arena of water scarcity [2], the role of experience in relation to residential water conservation behaviors lacks a plethora of empirical support. Based on this lack of research and coupled with evidence from one recent study [1], experience as a personal characteristic for behavioral outcomes will be primarily considered. Tversky and Kahneman's [3] cumulative prospect theory and Entman's [4] description of the message framing theory will also be discussed. Lastly, theoretical assumptions surrounding political ideology will be explored $[5,6]$. Based on these theoretical foundations, the interaction between these individual differences and message framing (gain and loss) will be examined in the context of the residential water use and conservation. This study hopes to provide descriptive and predictive information for public policy makers, water resource managers, and environmental researchers who focus on water issues, which in turn will help these actors make more informed and effective decisions regarding water legislation.

\section{Literature Review}

\subsection{Experiential Learning}

Prior experience with water shortages or other types of water issues play a vital role in whether people act to conserve it. Therefore, prior experience is of keen interest in the current study. Kolb's [6] experiential learning theory details how experience within one's environment can affect different processes of learning, which in turn can heavily influence the development of attitudes (i.e., positive perceptions of conservation) and behaviors (i.e., actually conserving) [7,8]. The theory details four steps in the experiential learning process, including (1) experiencing events within one's environment, (2) reflecting on those experiences, (3) formulating an abstract idea to guide future behaviors, attitudes, related experiences, and lastly, (4) executing behaviors based on the three previous steps $[7,8]$. Past research has called for the reporting of conservation research through ways that all members of a community can implement the findings, such as holding workshops to show people how to protect the environment by planting certain vegetation [2]. In addition, research examining experience with a crisis, such as a significant water shortage, perceptions about water conservation and conservation behaviors have found that those with more experience tend to find messages about water scarcity or water pollution more credible and be more likely to report the desire to conserve their water in the future [1]. In addition, personal experience with water scarcity in India has been examined, specifically looking at how individuals perceive specific water-saving techniques in their community by way of interviews, focus groups, and surveys [9]. This work found that personal experience with water scarcity led to negative perceptions of a large state-initiated watershed project [9].

Although research investigating experience and its influence on water conservation intentions and attitudes are rare, more research has examined relationships between certain experiences and intentions to engage in specific environmental behaviors. For example, one study found that individuals who experienced Hurricane Hugo-a category 5 storm that hit Guadeloupe, Saint Croix, Puerto Rico, and the Southeast United States in 1989 - reported increased intention to be prepared for future hurricanes [10]. Social science researchers have also examined whether, and if so, to what extent, experiences relevant to the changing climate (such as recognizing and experiencing "changes in seasons, weather, lake levels, animals and plants, and snowfall," [11] influence people's climate change attitudes and preventative behaviors related to other environmental issues like global warming, or climate change [11,12]. Namely, this research found that experience with a changing climate leads to higher levels of concern about climate change; yet only a fraction of residents in one region of the United States reported having experience with a changing climate. Importantly, though, experience with a changing climate led to 
higher levels of concern, and these experiences can be learned through actual experience, or even interactions with media messages [11]. Although global warming differs from water scarcity on several factors, the massive body of research on the topic can serve as a blueprint for the water scarcity research [1]. One robust finding from this work is the influential role that political worldviews can have on perceptions and attitudes of environmental-related topics [11,13-17]

Not everyone responds to the same experience in the same way. Scholars examining individual differences find that prior beliefs, values, dispositions, and attitudes can moderate the effect that certain experiences have on behaviors [18], and this is a particularly daunting challenge for science and environmental communication [19]. For example, scholars have also examined how motivated reasoning can impact the perceptions of experiential learning, and how increased levels of experience perceptions can lead to higher levels of concern and belief in an environmental issue like climate change [12]. Motivated reasoning is a concept that describes how individuals either accept or reject evidence based on their belief system [12]. For example, individuals who choose not to believe in climate change do so in contrary to the overwhelming scientific evidence, and most likely choose to side with their own ideology instead of the tangible, scientific evidence. These studies that examine how ingrained ideologies and experiences work towards increasing concern, understanding, and belief in important issues can give conservation managers a greater insight into what drives pro-conservation behavior $[5,12,20]$. In studies specific to environmental issues, research suggests that those who display higher levels of motivated reasoning, otherwise described as those that pick and choose details and facts based on their desired outcome, will show higher self-perceptions of experience [12]. In other words, those who are convinced their position is the correct one will also believe they have experience with the said issue, so that their desired outcome certainty is reinforced [12,21]. Overall, those who are less involved with an issue are more likely to learn through experience [12], which seems appropriate given that water scarcity was only mentioned by $5 \%$ of Americans who made changes in their daily lives to protect the environment, compared to $39 \%$ who would recycle more, and $17 \%$ who would drive less [22].

Although the social science surrounding experience and water conservation is scarce, past research has explored how experience with water scarcity and water quality can impact attitudes and behaviors [1]. Namely, this research found that those with a higher level of experience with residential water issues were more likely to conserve their water or take steps to preserve the quality of their water [1]. Individuals with more water scarcity experience also a reported feeling of more increased levels of emotion (i.e., anxiety and fear) in relation to water issues like scarcity and pollution, as well as more positive perceptions of credibility regarding news stories about water issues [1]. Based on Kolb's [6] description of the role that experience can play in the development of behavior, as well as past research surrounding experience, concern, and credibility $[1,9,10]$, the current study predicts that (H1) individuals with more water scarcity experience will be more likely to (a) change their conservation behavior, (b) be more concerned about water scarcity, and (c) view stories about water conservation as more credible, compared to those with less water scarcity experience.

\subsection{Prospect Theory}

Understanding the role that individual differences play in relation to residential water conservation is a key interest in this study. However, to help media practitioners, public policy makers, and resource managers effectively reach audiences and encourage conservation behaviors, we must determine the best way to craft conservation messages. One way to craft messages is to describe the situation, or "frame" it [23], in terms of a gain or loss. According to Tversky and Kahneman's [3] cumulative prospect theory, individuals make decisions based on whether their decision is likely to result in a gain or a loss.

Another aspect of the cumulative prospect theory involves the source from which the message is being framed. Certain sources who present either gains or losses can have an impact on the choice that is made, compared to other sources $[3,24]$. Further, individuals evaluate sources and the gain-loss 
message based on their own perceived level of intelligence. If a framed message is either above or below a person's perceived competence, that person is less likely to take the advice of the gain-loss message $[3,24]$. In relation to the intelligence levels, social science research has also detailed the role that a potential loss plays in comparison to a gain $[3,23]$. The cumulative prospect theory asserts that the perception of a loss is a far bigger weight on a potential decision than a gain [2]. An individual who perceives a potential loss is more likely to decide to avert that loss, compared to a faint perception of a potential gain. Although gain and loss framing may seem as a monetary issue, these frames can be utilized in a variety of environments. The prospect theory is mainly rooted in economics, but media psychologists and media practitioners writ large have extended the theory into a message feature realm based on the foundation that Tversky and Kahneman [3] have provided.

\subsection{Message Framing}

Borrowing in a large part from Tversky and Kahneman's [3] prospect theory, message framing scholars have examined how different frames in news stories can impact behavioral intentions [4] Message framing can be defined as, " ... to select some aspects of a perceived reality and make them more salient in a communicating text, in such a way as to promote a particular problem definition, causal interpretation, moral evaluation, and/or treatment recommendation for the item described," [4]. Within a text, for example, a news story, a journalist can frame an issue in several different ways. Entman [4] refers to an example in political news, where wartime journalism can either frame the solution as an immediate call-to-arms, or a subtler, sanctioned based solution to a problem. Although there are many different types of message frames surrounding many different issues, the current study is interested in an application of the framing theory, namely gain-loss framing, in the context of residential water conservation. Frames that use either a gain or a loss can be defined as presenting a problem to a person, for example water scarcity, and then emphasizing the outcome as either a gain (incentive on a water bill) or a loss (rate hike on a water bill).

Although there is not a plethora of research surrounding the framing theory in the context of water issues, there is an ample amount of research concerning the gain and loss message framing in other types of communication. Scholars have found that gain-framed messages increased the likelihood that individuals would use sunscreen on a public beach [25]. In addition, research has posited that tangible losses because of environmental concerns caused individuals to show a higher likelihood of exhibiting pro-environmental behavior [26]. Within the climate change communication literature, research finds that gain frames, compared to loss frames, can result in a higher likelihood of support for climate change legislation, as well as a more astute perception of the severity that the climate change can present [27]. Interaction effects have also been explored, namely between levels of uncertainty and gain-loss frames [28]. The results show that high levels of uncertainty related to the climate change, coupled with a gain frame, can result in more pro-environmental behaviors. Based on Tversky and Kahneman's [3] assertion within the cumulative prospect theory regarding the impact of different sources, as well as prior research within message framing and communication, the current study predicts that $(\mathrm{H} 2)$ individuals who view a news story about water conservation with a gain frame will be more likely to (a) change their conservation behavior, (b) be more concerned about water scarcity, and (c) view stories about water conservation as more credible compared to those who view a story with a loss frame.

\subsection{Political Ideology}

Like past research in social science surrounding water issues, climate change, ideology, and motivated reasoning $[1,12,13,17,29]$ the current study is also interested in how an individual's political ideology can impact the residential water usage. Political ideology is a set of attitudes that are both cognitive and motivational, and these underlying attitudes influence, sometimes very strongly, how people react to their social environments [5]. These reactions can influence interpersonal communication (i.e., talking to your neighbor, or family and friends), and more importantly, their voting 
behaviors. Past research also details a complex mental model in which political ideology acts as a gatekeeper for behaviors and their resulting outcome perceptions [20]. Political ideology can include a variety of views, values, and beliefs (e.g., individualism versus communitarianism, hierarchism versus egalitarianism, $[30,31]$, but one commonly studied is conservatism versus liberalism. Jost et al. [6] dissected conservatism and found that variables such as the desire for stability, resistance to new experiences and belief that the outside world is dangerous are positive predictors for the conservative attitude set, while these variables do not contribute to liberalism. Past studies have deconstructed liberalism and found that those who identify with this cognitive understanding put more emphasis on social issues and a reduction of social barriers, while also disregarding historical ways of thinking in favor of new, unique strategies [32]. Although each of these attitude sets contains specific and detailed motivational aspects, they are often measured on a Likert-type scale that asks participants to choose the response that best describes them: Very conservative, conservative, moderate, liberal, or very liberal. Importantly, political ideology can act as the system or tool that individuals use to communicate with the external environment regarding political attitudes and various behaviors, and these ideological attitudes can be influenced by one's desire to adhere to a social or political affiliation [6]. In other words, individuals are apt to rely on prepositions like political ideology when they must make decisions in real-time, and the more invested they are in the issue, the more likely they are to reach an outcome of their preference, (also otherwise referred to as motivated reasoning; [12,21,33]. Past research has shown that Liberals and Conservatives alter their policy and ideological attitudes to shape themselves with in-group members and their political party [34]. In other words, Liberals and Conservatives will support the same legislation or policy decision if they perceive that a political party (i.e., Democrat or Republican) that aligns with their ideology, supports the said legislation [34]. This is an example of how ideology and affiliation differ. Ideological beliefs are the building blocks of political affiliation, and these ideologies can transcend the party. However, this empirical research also demonstrates that social circles and identification with political parties can have a strong influence on political ideology.

Given these theoretical assumptions about political ideology, a vast amount of prior research has sought to provide a connection between ideological characteristics and behavior. Fishbein and Ajzen [35] have developed theories of behavior, specifically a reasoned action approach, that include political ideology as an important factor for predicting behavioral intentions as well as actual behaviors. Among other individual characteristics, political ideology has been posited to impact variables such as attitudes toward behaviors in general, perceptions regarding how much control individuals have over executing a certain behavior, and the perceived norms (e.g., descriptive and injunction) that surround a specific behavior [35]. The conceptualization of political ideology and the link between ideology and behavior are important discussions to have for the current study, and although there may not be a plethora of applications surrounding residential water conservation, there is an ample amount of research in the related field of environmental communication.

\subsection{Ideology and the Environment}

The link between political ideology, attitudes, and behavioral intentions is extensively studied in the environmental communication literature, and more specifically, the climate change communication research. Most of this empirical research utilizes a survey methodology to uncover how conservatism and liberalism can predict attitudes and behaviors. Past research has utilized behavioral theories in the context of issues like climate change and water conservation, specifically finding that attitudes and societal norms act as predictors for pro-environmental behavior [15,16]. Leiserowitz et al. [17] used an extensive questionnaire that contained items meant to measure belief in both the occurrence of climate change and the data being reported. The study found that a large percentage of Americans grew less concerned about climate change from 2008 to 2012, and that Conservatives were less likely to trust the scientists that offered the climate data compared to Liberals [17]. Dunlap, Xiao, and McCright [29] also found that Democrats were far more likely to express positive attitudes toward environmental issues than Republicans. 
Past empirical findings have established that social dynamics, mainly political ideology, influenced perceptions toward climate science $[13,14,36]$. For example, Conservatives with a greater scientific knowledge were more likely to have negative attitudes about climate change mitigation than Conservatives with lower levels of knowledge. Bak [37] also conducted a comprehensive review of survey results and found that education is not the most influential predictor of support for science in a politically polarized environment. These prior studies have provided social scientists with ample information regarding different environmental issues. These examples of how environmental behaviors are related with political ideology in the climate change literature have acted in many ways as a roadmap for social science research in the context of water conservation.

\subsection{Ideology and Water Usage}

Although the current study hopes to fill a gap in the residential water conservation research, there are noteworthy water studies available from social science in contexts other than residential water usage. Past research has used field experiments to test what type of messages (i.e., PSA's and public information brochures) decreased the household water usage, finding that intervening in households by distributing media messages about water conservation resulted in less water usage compared to groups that didn't receive a message [38,39]. Other work found that those who felt they had a collective or personal control to achieve a desirable solution were more likely to report that they would conserve water in the future [16]. In the context of political ideology and water conservation attitudes and behaviors, social science researchers utilized research in climate change communication to predict how Liberals and Conservatives would react to water scarcity and water quality news stories [1]. The findings suggested that Liberals were more likely to enact pro-water conservation behaviors compared to Conservatives [1]. Based on this small amount of research surrounding political ideology and water conservation behaviors, coupled with the ample amount of research in the climate change literature, the current study predicts that $(\mathrm{H} 3)$ after reading a short news story related to water scarcity, the more Liberal a person scores on a continuous scale, they will be more likely to (a) change their conservation behavior, (b) be more concerned about water scarcity, and (c) view stories about water conservation as more credible.

\section{Methodology}

To test the above hypotheses, we conducted an experiment in which participants were randomly assigned to read one message, designed to look like a short news story, that emphasized either an economic gain (i.e., residents would receive a check for having conserved water) or loss (i.e., residents would be taxed for not conserving water). Then, participants answered a series of questions about what they read, including their intention to conserve water, and demographic questions (including questions about their political ideology and political affiliation). We describe the study in more detail below.

\subsection{Participants}

Participants were recruited from Amazon's Mechanical Turk (MTurk). Although not nationally representative, MTurk samples have been shown to be more diverse than recruiting participants through networking or at a local community center (i.e., convenience sampling) [40] and are comparable to other internet-based samples like those from the Survey Sampling International (SSI), or other types of survey distributors. [41,42]. Concerns exist about the use of internet samples, such as inattention and non-human responders (e.g., "bots"), so to address these concerns, the questionnaire contained a quality-control question, which asked, "For quality control purposes, please select 'strongly agree."' A total of 56 participants did not pass the quality-control test and were excluded from the study, leaving a total of 466 participants for analysis.

The final sample was demographically diverse. Regarding gender, $56.2 \%$ of the participants were male and $43.8 \%$ of the participants were female. In terms of education, $1.1 \%$ of the participants had an education level equal to attending some high school, $7.6 \%$ of the participants held a high school 
degree, $23.9 \%$ of the participants attended some college to date, $51.2 \%$ of the participants held an undergraduate degree, and $16.3 \%$ of the individuals held a post-graduate degree. Overall, $14.9 \%$ of the participants made less than $\$ 15,000$ a year, $17.7 \%$ make between $\$ 15,001$ and $\$ 30,000$ a year, $20.5 \%$ of the participants make between $\$ 30,001$ and $\$ 45,000$ every year, $15.7 \%$ make between $\$ 45,001$ and $\$ 60,000$ a year, $11.4 \%$ of the participants make $\$ 60,001$ and $\$ 75,000$ each year, and $19.8 \%$ of the participants made over $\$ 75,000$. When asked about race/ethnicity, $62.2 \%$ reported being White or Caucasian, $5.8 \%$ reported being Black or African-American, 5.6\% reported being Hispanic or Latino, 24.5\% reported Asian, and 1.7\% selected Other. In terms of political ideology, 27.3\% identified as Conservative, $29.4 \%$ selected Moderate, and $43.4 \%$ identified as Liberal.

\subsection{Procedure}

The study was built using the Qualtrics software and was linked using an anonymous URL on the MTurk website. "Workers" within the MTurk database saw a short description about the study and could choose whether to participate by clicking the link. If they chose to participate, participants clicked on the anonymous URL link and were paid 50 cents upon completion.

Once a participant clicked the link, they were taken to a screen that asked them to agree to participate in the study. Once they agreed, they were randomly assigned to either the gain or loss message framing condition. These conditions consisted of short news stories under 250 words in length. Each news story presented the water scarcity problem and then presented the solution, which was either a personal economic gain or personal economic loss. The gain solution was presented as a benefit to individuals and the economy writ large. The gain frame was worded so that if a person conserved their water and it was reflected on their water bill, that person would be presented with a check each month in the mail. The loss frame was worded as if the person did not meet the residential water conservation levels on each water bill, they would be taxed on each water bill. The authors of the news stories were fictitious, and the sources used in the news stories were also fictitious.

After participants read these short news stories, they filled out a questionnaire that included items asking about news report credibility, issue concern, behavioral intentions, political ideology, experience with water scarcity, and finally demographics. After the questionnaire was completed, participants were debriefed that these solutions were not proposed now, and that the content in the news stories was fictional. Participants were then paid for their time.

\subsection{Measurements}

The three dependent (outcome) measures examined in this study were news credibility [43], concern [1], and intentions to engage in conservation behaviors [35]. The three major dependent variables were measured on semantic differentials scales scored so that zero represented the negative adjective and 10 represented the positive adjective. To ensure that the dependent measures were indeed separate constructs, a parallel analysis was conducted. This test suggested that there were three different factors, and a follow-up factor analysis with promax, or oblique, rotation (as the factors were expected to be correlated) demonstrated that each scale loaded onto its own factor. See Figure 1 and Table 1. 


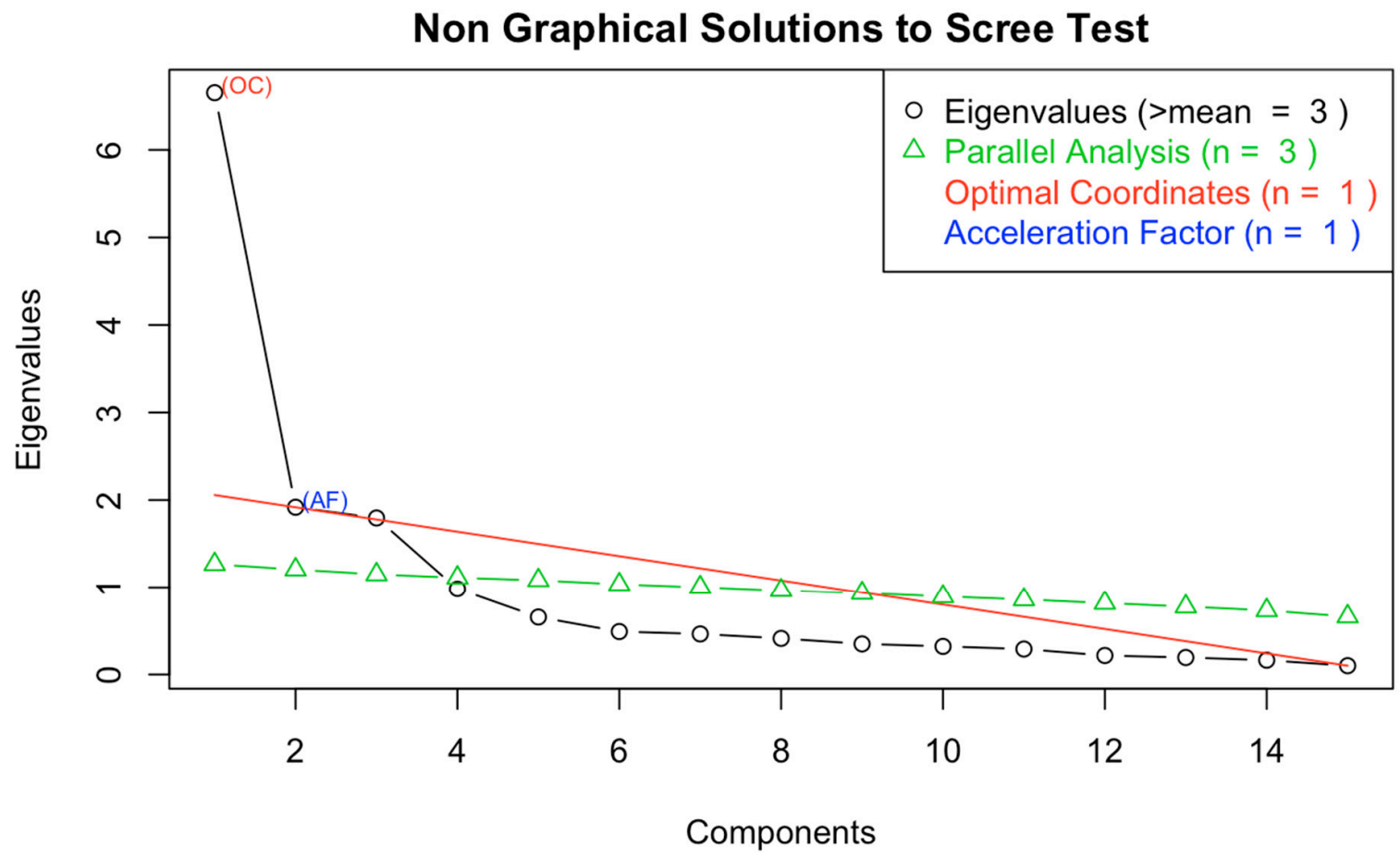

Figure 1. Possible solutions to the number of factors. Both the eigenvalues and parallel analyses suggest a three-factor solution.

Table 1. Factor loadings for all dependent measures.

\begin{tabular}{|c|c|c|c|}
\hline & Factor 1 & Factor 2 & Factor 3 \\
\hline \multicolumn{4}{|c|}{ News Story Credibility } \\
\hline RC1. “Fair" & 0.79 & & \\
\hline RC2. "Biased" & 0.19 & & 0.15 \\
\hline RC3. "Whole Story" & 0.66 & & \\
\hline RC4. "Accurate" & 0.86 & & \\
\hline RC5. "Fact/Opinion" & 0.80 & & \\
\hline RC6. “Trusted" & 0.86 & & \\
\hline RC7. "Public Interest" & 0.82 & & \\
\hline RC8. “Factual” & 0.88 & & \\
\hline \multicolumn{4}{|c|}{ Intent to Conserve Water } \\
\hline BI1. "Definitely Do" to "Definitely Do Not" & & 0.91 & \\
\hline BI2. "Likely To" to "Unlikely To" & & 0.97 & \\
\hline BI3. "Agree" to "Disagree" & & 0.82 & \\
\hline \multicolumn{4}{|c|}{ Concern about Water Scarcity } \\
\hline WS1. "Severe" & & & 0.75 \\
\hline WS2. “Harm” & & & 0.65 \\
\hline WS3. "Important" & & & 0.80 \\
\hline WS4. "Believable" & & & 0.70 \\
\hline Proportion of Variance & 0.31 & 0.17 & 0.14 \\
\hline
\end{tabular}

\subsubsection{News Story Credibility.}

Of the eight news story credibility items, seven strongly loaded onto the factor (Factor 1): Excluding only the reversed coded "biased" item. Therefore, this item was dropped from the scale. These items showed a strong inter-item reliability (Cronbach's $\alpha$ of 0.93 ) and were averaged to create and index the news story credibility $(M=6.06$ of $10, S D=2.02)$. 


\subsubsection{Intent to Conserve}

The outcome variable, intent to conserve water (Factor 2), showed strong loadings for all three items (i.e., intent to conserve water, certainly will conserve water, willingness to conserve water) and strong inter-item reliability (0.93). Responses to these questions were averaged to create an index of intent to conserve water $(M=6.73$ of $10, S D=2.75)$.

\subsubsection{Concern about Water Scarcity}

The outcome variable concern about water scarcity (Factor 3) showed strong loadings for the original four items: Severe threat, likely to harm me, important problem, and believable. These items were averaged to create an issue concern, which registered a Cronbach's $\alpha$ of 0.812 .

\subsubsection{Experience with Water Scarcity}

To capture experience with water scarcity, participants answered two questions using a seven-point Likert-type scale $(1=$ strongly disagree to 7 = strongly agree): "Water scarcity has personally affected me," and "Water scarcity has affected my family or friends." These items were strongly correlated with one another (Spearman's $\varrho=0.86$ ) and were then averaged to form a scale of experience with water scarcity $(M=6.97$ of $10, S D=1.93)$. This variable was standardized so that participants scores reflected their experience with water scarcity relative to the rest of the sample $(M=0 ; S D=1$; range $=-1.07$ to 2.1 , skew $=0.73$.

\subsubsection{Political Ideology}

To capture the political ideology, participants answered two questions. One asked about the participants' ideology on a five-point, Likert-type scale from very liberal (1) to very conservative (5). Another asked each participant whether they affiliated with the Democratic $(n=216)$ or Republican $(n=108)$ parties with options to select that they were politically independent $(n=121)$ or aligned with another political party $(n=18)$. This item was recoded so that " 1 " was equal to affiliating with the democratic party, " 3 " was equal to affiliating with the Republican party, and people who are politically independent or another party were in the middle (2). Ideology and party affiliation were moderately correlated (Spearman's $\varrho=0.49$ ) and were standardized and averaged to create an index of political ideology. This variable was re-standardized so that participants' scores represented their political ideology relative to the rest of the sample $(M=0, S D=1$, range $=-3$ to 2.62 , skew $=0.28)$. Note that adding or dropping the "biased" item from the news credibility index, does not significantly change the results.

\section{Results}

To examine the hypotheses, for each outcome variable we conducted a general linear model (controlling for age, gender, education, race, ethnicity, and income), and the results we report are based on the Type III sums of squares. To examine the relative importance of each factor, we also report the $\mathrm{R}^{2}$ contribution averaged among regressors $[44,45]$. These values are adjusted so that the percentages reported reflect the percent of the total variance explained by the model that is accounted for by that variable. All analyses were conducted in R [46].

\subsection{Concern about Water Scarcity}

The total response variance in the reported concern about water scarcity was equal to 3.77 , and the model predicted $17.8 \%$ of the response variance. Participants who read the message with the "gain" frame $(M=7.09, S D=1.82)$ reported a marginally more concern about water scarcity than those who read the message with the "loss" frame $(6.85, \mathrm{SD}=2.02), F(1,438)=3.96, p=0.047$. This variable accounted for $3.17 \%$ of the $17.8 \%$ of the variance explained (or, $0.56 \%$ of the total response variance). The political ideology did not significantly predict concern about water scarcity, $F(1,438)=0.18$, 
$p=0.669$, and it accounted for $2.75 \%$ of the $17.8 \%$ of the variance explained $(0.49 \%$ of the total response variance). Experience was much more influential: Participants who reported having experienced water scarcity issues were more likely to be concerned about water scarcity, $F(1,438)=64.40, p<0.001$, and it accounted for $77 \%$ of the $17.8 \%$ of the variance explained ( $13.74 \%$ of the total response variance). See Figure 2.

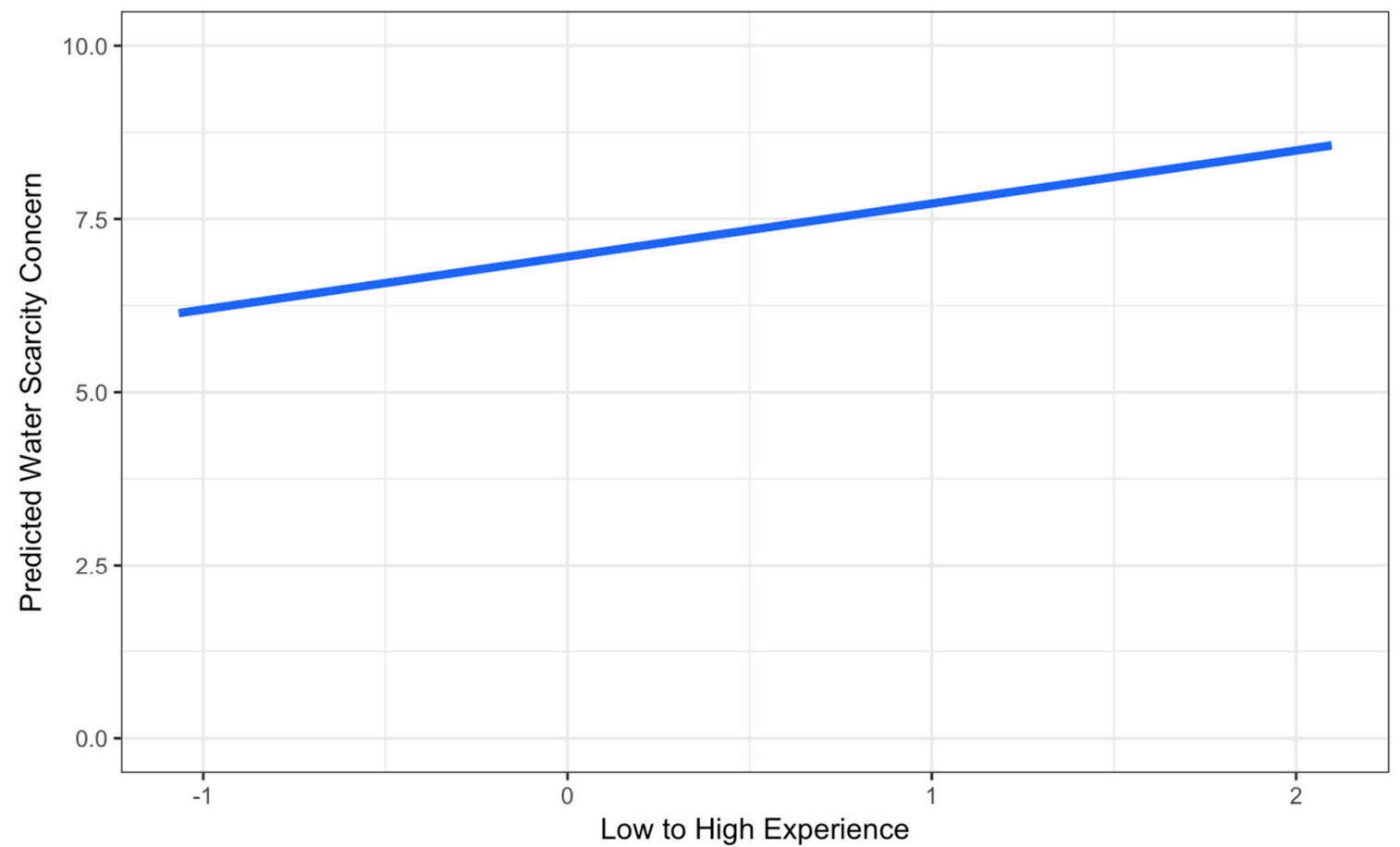

Figure 2. Positive relationship between the experience with water scarcity and concern about water scarcity. Predicted values are displayed.

\subsection{Perception of Message Credibility}

The total response variance for the perceptions of message credibility was equal to 4.12 and the model explained $9.21 \%$ of the variance. Participants who read the message with the "gain" frame $(M=6.26, S D=1.96)$ reported more perceived message credibility than those who read the message with the "loss" frame $(\mathrm{M}=5.86, \mathrm{SD}=2.06), F(1,426)=8.16, p=0.005$. This variable accounted for $16.47 \%$ of the explained variance ( $1.52 \%$ of the total response variance). The political ideology predicted the perceived message credibility, $F(1,426)=4.067, p=0.031$, and accounted for $17.22 \%$ of the explained variance (1.59\% of the total response variance). As with the predicting concern, experience was much more influential. Participants who reported having experienced water scarcity issues perceived the message as more credible, $F(1,426)=21.48, p<0.001$, and it accounted for $57.18 \%$ of the explained variance ( $5.27 \%$ of the total response variance). See Figure 3. 


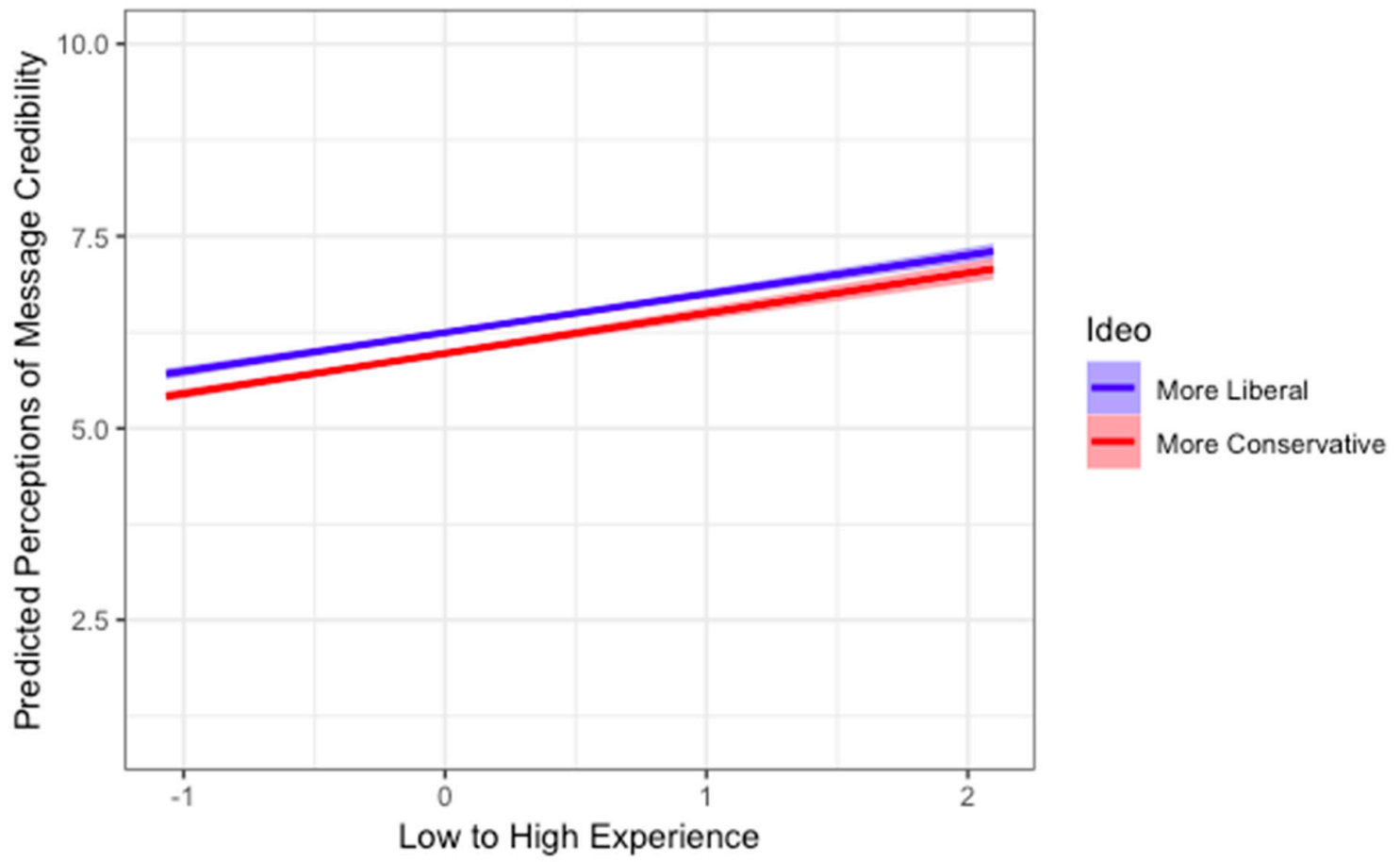

Figure 3. Higher levels of experience significantly predict perceptions of the message credibility, regardless of the political ideology. Predicted values are displayed.

\subsection{Intent to Engage in Water Conservation}

The total response variance for the intention to engage in conservation behaviors in the future was equal to 7.37 and the model explained $11.4 \%$ of the variance. Unlike the water scarcity concern and credibility, there were no significant differences between the people who read the message with the "gain" frame $(M=6.66, S D=2.82)$ and those who read the message with the "loss" frame $(M=6.79$, $S D=2.68), F(1,437)=0.001, p=0.972$. This variable accounted for $0.2 \%$ of the explained variance $(0.03 \%$ of the total response variance). The political ideology also did not significantly predict the intent to engage in conservation behaviors, $F(1,437)=0.035, p=0.851$, and accounted for $1.16 \%$ of the explained variance $(0.13 \%$ of the total response variance). Again however, experience was much more influential. Participants who reported having experienced water scarcity issues reported that they intended to engage in conservation behaviors in the future, $F(1,437)=30.35, p<0.001$, which accounted for $59.50 \%$ of the explained variance (6.78\% of the total response variance). See Figure 4 and Table 2 . Figure 5 provides a visual representation of the relative importance of each of the variables in predicting the outcomes measured. From this, of the variables measured, experience is the most paramount. While concern about water scarcity accounted for the most variance in the model (17.8\%) compared to the perceived credibility $(9.21 \%)$ and intentions $(11.4 \%)$, this was not incredibly surprising given the political nature of environmental behavior, where concern about the issue seems to reign supreme over action. 


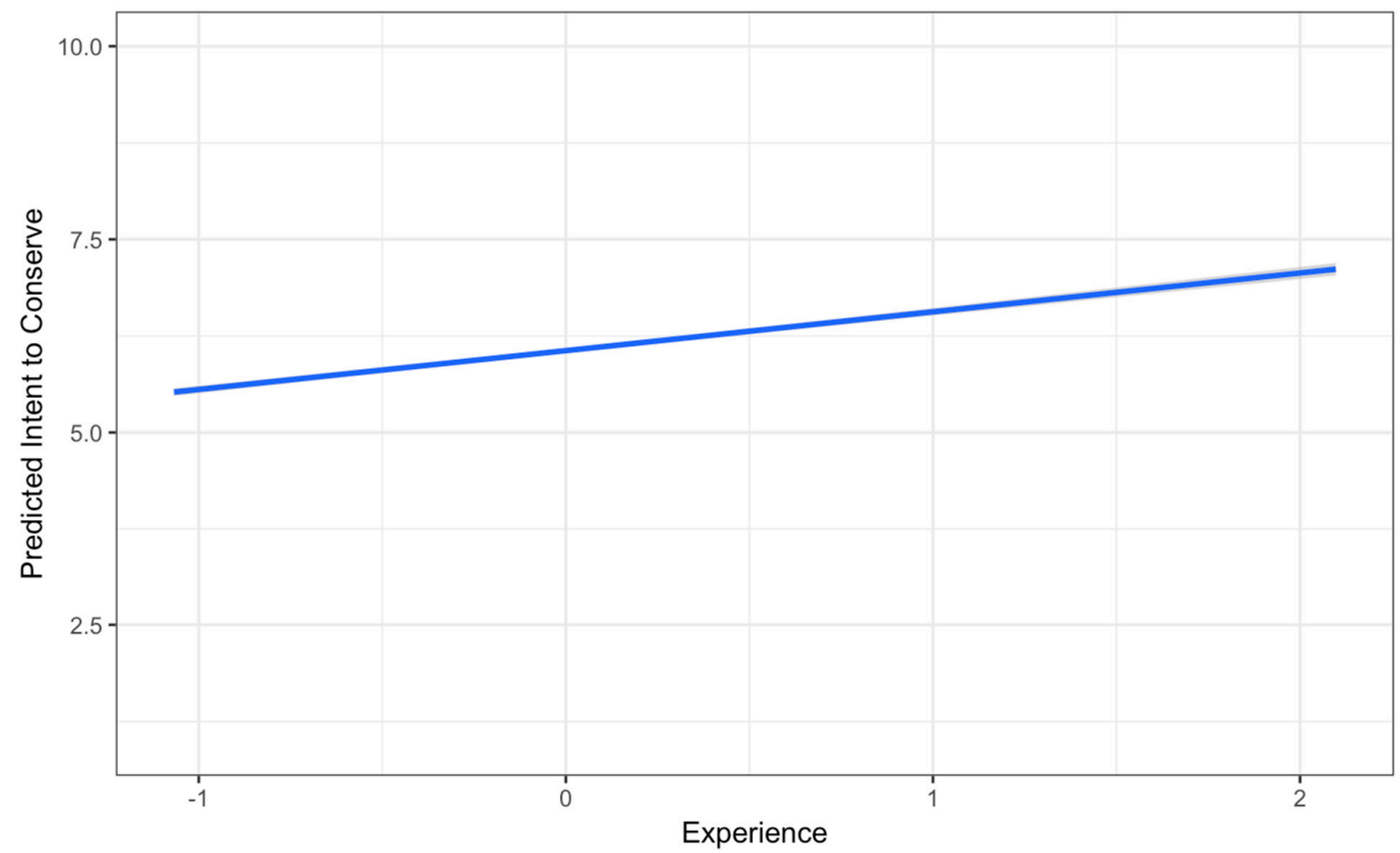

Figure 4. Results of the general linear model, showing that the level of experience predicts a person's intention to conserve water.

Table 2. F values for each of the variables for each of the three general linear models. Significance is indicated with asterisks ( $\left.{ }^{\mathrm{t}} p<0.10,{ }^{*} p<0.05,{ }^{* *} p<0.01,{ }^{* * *} p<0.001\right)$ and is based on the Type III sums of squares.

\begin{tabular}{cccc}
\hline & Water Scarcity & Credibility & Intent to Conserve \\
\hline Frame & $\boldsymbol{F}$ & $\boldsymbol{F}$ & $\boldsymbol{F}$ \\
\hline Political Ideology & $3.96^{*}$ & $8.16^{* *}$ & 0.00 \\
\hline Experience & 0.18 & $4.67^{*}$ & 0.04 \\
\hline Income & $64.40^{* * *}$ & $21.48^{* * *}$ & $30.35^{* * *}$ \\
\hline Gender (Male) & 0.35 & 0.13 & 0.33 \\
\hline Education & $4.42^{*}$ & 0.85 & $6.28^{*}$ \\
\hline Black & $2.98^{\mathrm{t}}$ & 0.81 & $3.35^{\mathrm{t}}$ \\
\hline Hispanic & 0.39 & 0.35 & 0.39 \\
\hline Age & 0.89 & 0.91 & 0.02 \\
\hline Total Variance Explained & 1.51 & 0.11 & $10.95^{* *}$ \\
\hline
\end{tabular}




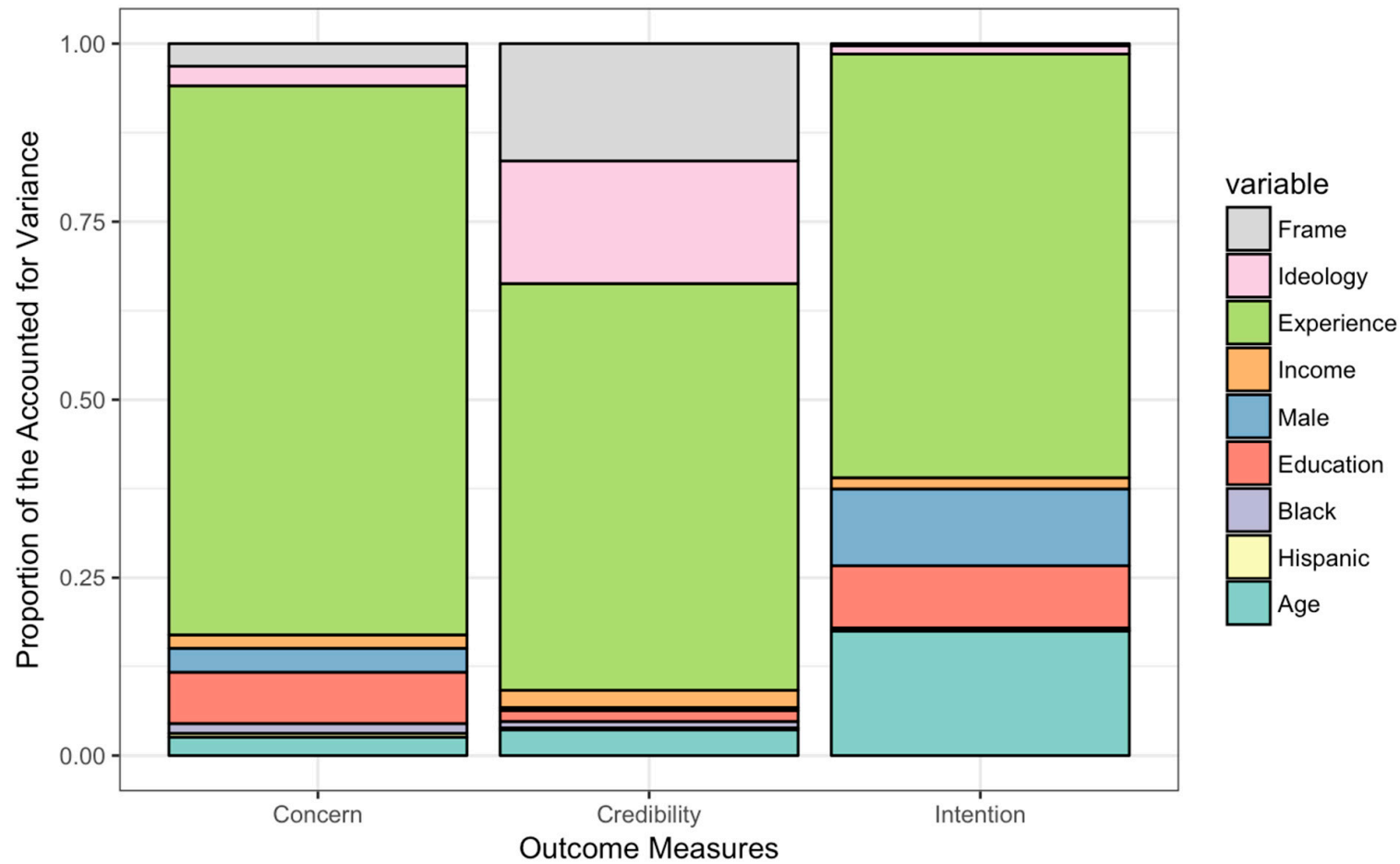

Figure 5. Visual representation of the proportion of the total variance accounted for that can be explained by each of the individual difference variables.

\section{Discussion}

Conserving our natural resources is imperative to protecting and maintaining our planet. Conservation, a broad term, can entail many different types of activities, but the current study focused on the residential-level conservation of water, examining the role of various individual-level factors. Disciplines like engineering and hydrology are vital for conserving water, but certain human factors also play a crucial role in conservation. These factors are vital for public policy makers when communicating the importance of water conservation to community members, lobbyist, and the general public. This study contributes to the literature by examining the relative importance of various human factors (as well as a type of message) on people's intent to conserve water. We found that prior experience with water scarcity is key, predicting higher levels of concern about water scarcity, more positive perceptions of message credibility related to water conservation, and more importantly, a higher likelihood of conserving water in the future.

Past conservation research has detailed how to communicate results about water scarcity to the public, namely by showing the public that pro-environmental behaviors can help conserve natural resources [2]. However, the role of individual characteristics in the realm of water conservation is a scarcely examined phenomenon, and these findings are important for a variety of reasons. First, these results extend the experiential learning theory to the context of water conservation $[7,8]$. Portions of the experiential learning theory detail how individuals learn from experiences within their environment, and importantly, how individuals shape future decisions based on these experiences $[7,8]$. Overall, this makes sense in the context of water conservation. If a person has experienced water scarcity through a first-hand experience of not having enough water for landscaping or having to xeriscape their lawn, that person should exhibit more concern about water scarcity and be more likely to conserve water in the future. The results from this study bear this assumption out, bolstering past social science research [1]. Further, the current study also found that messages about water scarcity were viewed as more credible by those with higher levels of scarcity experience. 
These findings related to water scarcity and experience are not only important for theoretical implications, but they are extremely important for conservation managers and policy makers. For global conservation managers, it is vital to understand the nuanced characteristics of publics they mean to communicate with, and further, knowing that higher levels of experience can predict concern, credibility perceptions, and conservation behavior provides valuable information for these managers. If they are communicating with publics who have documented experience with water scarcity, these conservation managers can approach the problem knowing that these publics have initial levels of concern and intentions to conserve. In addition, conservation managers can assume that the messages they distribute to publics with high levels of scarcity experience will view these messages as credible, which has long been established as an important message characteristic in persuasion [47-49]. On the contrary, if global conservation managers are dealing with publics who are not experienced with water scarcity, whether that be first or second-hand experience, these managers will need to design messages to raise levels of concern and intentions to conserve, and distribute messages knowing that the perceived credibility of the communication may be lacking. These messages may consist of more blatant warnings about the availability of water for residential and agricultural areas, and what those consequences may mean for future generations. Further, messages for inexperienced publics may need more abrasive messaging (i.e., videos) compared to textual messaging that is sufficient for experienced publics. These findings related to experience and water conservation are important on a global scale; however, these results must be replicated in other cultures where water conservation is a pressing issue (i.e., India and Australia).

Apart from the effects of experience, which were the most influential in the variance accounted for, this study also examined how certain message frames can impact the concern, perceptions of message credibility, and intent to conserve. Past research in economics has shown that frames that exhibit a net-gain will elicit more positive outcomes compared to frames that result in a loss $[3,23,24]$, and research in communication has also extended these findings in the realm of message framing $[4,25,26]$. The current study found that news stories that offered a narration of a net-gain, meaning that if a person conserves their water they will gain a credit on their monthly water bill, resulted in higher levels of concern about water scarcity and more positive perceptions of credibility of the message. However, this study did not find that gain versus loss frames predicted the intention to conserve water.

Although framing did not impact behavioral intentions, global policy makers and resource managers can use these findings when tailoring messages about water conservation. The lack of a framing impact on behavioral intentions could be explained by examining the type of loss that was used in the messages, namely a higher water bill. More substantial losses should possibly be used in future framing research in the area of water conservation to elicit more salient intentions, such as no drinking water for future generations that results in an extreme like loss of life, or less water for agriculture, which results in less food for certain populations. Using messages that detail the positive gains that result from conserving water should elevate concern about water scarcity, and individuals who read these stories will view them as more credible. As stated above, the perceived credibility is a vital potion of the persuasion model $[47,48]$, and these findings will remove hurdles for policy makers when they're communicating with publics about water conservation. If a global resource manager or conservation communicator knows that a gain frame will elicit more concern about water scarcity and positive perceptions of message credibility, then that manager can focus their strategy on other mitigating factors such as support for local policy changes. Knowing that gain frames raise the levels of concern and perceptions of credibility are two vital pieces of information for global conservation managers in the realm of water scarcity.

There were also significant relationships between the demographic variables and outcome variables. Although this was not within the primary scope of the current study, it is important to discuss and acknowledge some of these results. As age increased, so did a participant's willingness to conserve water. There are a number of reasons why this may be the case. First, older individuals may 
in turn have more experience with environmental crisis, and thus are more likely to conserve their water to protect future generations. On the contrary, younger participants may have a narrower scope of impact compared to older participants, which leads them to show a lower level of concern about water scarcity and less likelihood of conserving water. Further, education accounted for more variance in the concern and intention compared to perceived credibility. Higher levels of education should result in higher levels of media literacy, and thus persuasive messages about water conservation may be viewed as less credible by those with higher levels of education. In other words, the concern and intention to conserve water may already be present within educated publics, so the persuasiveness of the message, or the credibility, may be nonconsequential. In terms of geographical location, the zip code was recorded during measurement, but there doesn't seem to be a valuable tool available to researchers to compliment the experimental data with the geographical location. Further interdisciplinary work should be done between the geoscience and social science to close this gap.

Lastly, this study examined how political ideology can impact the concern, message credibility, and intent to conserve. Overall, the findings suggest that political ideology only predicted perceptions of message credibility. The more Liberal a person scored on the continuous scale (standardized to include ideology and affiliation), the more likely they were to find messages about water scarcity as credible. This is important for campaign specialists, others who are crafting messages related to residential water conservation, and public policy makers, because understanding your publics is essential to crafting an effective message. Take, for example, the municipality of Austin, TX, who recently broke news that they are running out of city water supplies [50]. This area of Texas (Travis County) is historically liberal, so messages from news sources or public relations agencies expressing the need to conserve water should be viewed as more credible compared to more conservative districts or counties. Further, the sample collected was skewed Liberal. This may have an impact on how the variance accounted for in the model will flesh out in the future, but should still be of use to general populations that skew Liberal or Conservative. In future research, ANCOVA's may be used to control for political ideology, so that results can be discussed when this individual difference is held constant.

Overall, these findings have serious ramifications for a large number of publics. In order to make real change in the realm of water conservation, serious discussions surrounding public policy need to occur. Public policy can work to conserve water on small and large scales, from legislation in municipal areas to federal initiatives surrounding agricultural practices. Based on these findings, policy makers, resource managers, and communication specialists can make informed and strategic decisions when discussing water conservation with communities and large publics. Enacting water policies is a vital step for protecting residential and agricultural water resources, but those policies need support among various publics in order to be effective and survive. The data and discussions here should provide the safety net that policy makers need when stimulating support among residential water users.

While the past social science research found that the concern and intent to conserve water was predictable along ideological lines [1], the current study, through different statistical procedures, found that experience was much more of a predictor than ideology related to those outcomes. Namely, while there was little difference within the results for water scarcity concern, the difference of variance accounted for within concern by experience was exponentially more impactful compared to perceived credibility and intention. The current study contends that both experience and political ideology should be considered when communicating with communities about residential water conservation. Although the finding that ideology predicts perceptions of message credibility is of note for resource managers, this finding must be viewed in tandem with the stronger impact of experience, and the notable predictability of message framing.

\section{Conclusions}

Overall, this study achieved a few things. First, theories such as experiential learning and framing were combined with concepts such as political ideology to examine residential water conservation behaviors. This theoretical application to water conservation is largely nuanced in the environmental 
communication literature and should provide the groundwork for future social science research applying other various theories in the context of conservation. Next, this study provides applicable findings for those who are tasked with influencing and promoting residential water conservation, namely public policy makers, resource managers, and researchers. These experts can use these findings when communicating with specific communities about water, and further, they can develop successful message campaigns to protect our global water resources based on these findings. Creating and reinforcing the support for water policy will not only result in more legislation, but should also form positive changes in our water management practices. Lastly, all scientific disciplines must work together to preserve our planet. Whether that be the biological sciences or the social sciences, the interdisciplinary work can only benefit and preserve our environment. Water is a vital global resource and finding successful ways to promote the conservation of this resource seems like a worthwhile endeavor to pursue.

Author Contributions: Each author contributed in different, but important ways. The different contributions are as follows: conceptualization, D.H. and K.J., methodology, D.H. and K.J., software, D.H. and A.L., validation, D.H. and A.L., investigation, D.H., K.J., A.L., formal analysis, D.H. and A.L., resources, D.H., K.J., and A.L., data curation, D.H. and A.L., writing - original draft preparation, D.H., K.J., A.L. writing - eview and editing, D.H., K.J., A.L., visualization, A.L., supervision, D.H., A.L., project administration, D.H., funding acquisition, D.H., K.J., A.L.

Funding: This research received no external funding.

Acknowledgments: The authors would like to thank the University of Tennessee and Texas Tech University for providing a productive environment for executing this research.

Conflicts of Interest: The authors declare no conflict of interest.

\section{References}

1. Callison, C.; Holland, D. Impact of Political Identity and Past Crisis Experience on Water Attitudes. J. Contemp. Water Res. Edu. 2017, 161, 19-32. [CrossRef]

2. Bennett, N.J.; Roth, R.; Klain, S.C.; Chan, K.; Christie, P.; Clark, D.A.; Cullman, G.; Curran, D.; Durbin, T.J.; Epstein, G. Conservation social science: Understanding and integrating human dimensions to improve conservation. Biol. Conserv. 2017, 205, 93-108. [CrossRef]

3. Tversky, A.; Kahneman, D. Advances in prospect theory: Cumulative representation of uncertainty. J. Risk Uncertain. 1992, 5, 297-323. [CrossRef]

4. Entman, R.M. Framing: Toward clarification of a fractured paradigm. J. Commun. 1993, 43, 51-58. [CrossRef]

5. Jost, J.T. The end of the end of ideology. Am. Psychol. 2006, 61, 651. [CrossRef] [PubMed]

6. Jost, J.T.; Napier, J.L.; Thorisdottir, H.; Gosling, S.D.; Palfai, T.P.; Ostafin, B. Are needs to manage uncertainty and threat associated with political conservatism or ideological extremity? Personal. Soc. Psychol. Bull. 2007, 33, 989-1007. [CrossRef] [PubMed]

7. Kolb, D.A. Experiential Learning: Experience as the Source of Learning and Development; Prentice-Hall: Englewood Cliffs, NJ, USA, 1984.

8. Kolb, A.Y.; Kolb, D.A. Experiential learning theory. In Encyclopedia of the Sciences of Learning; Springer: Boston, MA, USA, 2012; pp. 1215-1219.

9. Bharucha, Z.P.; Smith, D.; Pretty, J. All paths lead to rain: Explaining why watershed development in India does not alleviate the experience of water scarcity. J. Dev. Stud. 2014, 50, 1209-1225. [CrossRef]

10. Sattler, D.N.; Kaiser, C.F.; Hittner, J.B. Disaster Preparedness: Relationships Among Prior Experience, Personal Characteristics, and Distress 1. J. Appl. Soc. Psychol. 2000, 30, 1396-1420. [CrossRef]

11. Akerlof, K.; Maibach, E.W.; Fitzgerald, D.; Cedeno, A.Y.; Neuman, A. Do people "personally experience" global warming, and if so how, and does it matter? Glob. Environ. Chang. 2013, 23, 81-91. [CrossRef]

12. Myers, T.A.; Maibach, E.W.; Roser-Renouf, C.; Akerlof, K.; Leiserowitz, A.A. The relationship between personal experience and belief in the reality of global warming. Nat. Clim. Chang. 2013, 3, 343. [CrossRef]

13. Hamilton, L.C. Education, politics and opinions about climate change evidence for interaction effects. Clim. Chang. 2011, 104, 231-242. [CrossRef] 
14. McCright, A.M.; Marquart-Pyatt, S.T.; Shwom, R.L.; Brechin, S.R.; Allen, S. Ideology, capitalism, and climate: Explaining public views about climate change in the United States. Energy Res. Soc. Sci. 2016, 21, 180-189. [CrossRef]

15. Tikir, A.; Lehmann, B. Climate change, theory of planned behavior and values: A structural equation model with mediation analysis. Clim. Chang. 2011, 104, 389-402. [CrossRef]

16. Lam, S.P. Predicting intention to save water: Theory of planned behavior, response efficacy, vulnerability, and perceived efficiency of alternative solutions 1. J. Appl. Soc. Psychol. 2006, 36, 2803-2824. [CrossRef]

17. Leiserowitz, A.A.; Maibach, E.W.; Roser-Renouf, C.; Smith, N.; Dawson, E. Climategate, public opinion, and the loss of trust. Am. Behav. Sci. 2013, 57, 818-837. [CrossRef]

18. Oliver, M.B.; Krakowiak, K.B. Individual differences in Media Effects. In Media Effects: Advances in Theory and Research, 3rd ed.; Bryant, J., Oliver, M.B., Eds.; Lawrence Erlbaum Associates: Mahwah, NJ, USA, 2009.

19. Akin, H.; Landrum, A.R. A Recap: Heuristics, Biases, Values and Other Challenges to Communicating Science. In Oxford Handbook of the Science of Science Communication; Jamieson, K.H., Scheufele, D.A., Kahan, D.M., Eds.; Oxford University Press: New York, NY, USA, 2017; pp. 455-460.

20. Denzua, A.T.; North, D.C. Shared mental models: Ideologies and institutions. In Elements of Reason; Lupia, A., McCubbins, M.D., Popkin, S.L., Eds.; Sage: Newbury Park, CA, USA, 2000.

21. Kunda, Z. The case for motivated reasoning. Psychol. Bull. 1990, 108, 480. [CrossRef]

22. Gallup. Many environmental issues at 20-year low concern. Available online: http:www.gallup.com/poll/ 126716/environmental-issues-year-low-concern.aspx (accessed on 9 September 2019).

23. Tversky, A.; Kahneman, D. Rational choice and the framing of decisions. J. Bus. 1986, 59, 251-278. [CrossRef]

24. Heath, C.; Tversky, A. Preference and belief: Ambiguity and competence in choice under uncertainty. J. Risk Uncertain. 1991, 4, 5-28. [CrossRef]

25. Detweiler, J.B.; Bedell, B.T.; Salovey, P.; Pronin, E.; Rothman, A.J. Message framing and sunscreen use: Gain-framed messages motivate beach-goers. Health Psychol. 1999, 18, 189. [CrossRef]

26. Davis, J.J. The effects of message framing on response to environmental communications. J. Mass Commun. Q. 1995, 72, 285-299. [CrossRef]

27. Spence, A.; Pidgeon, N. Framing and communicating climate change: The effects of distance and outcome frame manipulations. Glob. Environ. Chang. 2010, 20, 656-667. [CrossRef]

28. Morton, T.A.; Rabinovich, A.; Marshall, D.; Bretschneider, P. The future that may (or may not) come: How framing changes responses to uncertainty in climate change communications. Glob. Environ. Chang. 2011, 21, 103-109. [CrossRef]

29. Dunlap, R.E.; Xiao, C.; McCright, A.M. Politics and environment in America: Partisan and ideological cleavages in public support for environmentalism. Environ. Politics 2001, 10, 23-48. [CrossRef]

30. Douglas, M.; Wildavsky, A.B. Risk and Culture: An Essay on the Selection of Technical and Environmental Dangers; University of California Press: Oakland, CA, USA, 1982.

31. Kahan, D.M.; Braman, D.; Slovic, P.; Gastil, J.; Cohen, G. Cultural cognition of the risks and benefits of nanotechnology. Nat. Nanotechnol. 2009, 4, 87. [CrossRef] [PubMed]

32. Kerlinger, F.N. Liberalism and Conservatism: The Nature and Structure of Social Attitudes; Lawrence Erlbaum Assoc Incorporated: Mahwah, NJ, USA, 1984.

33. Redlawsk, D.P. Hot cognition or cool consideration? Testing the effects of motivated reasoning on political decision making. J. Politics 2002, 64, 1021-1044. [CrossRef]

34. Cohen, G.L. Party over policy: The dominating impact of group influence on political beliefs. J. Personal. Soc. Psychol. 2003, 85, 808. [CrossRef]

35. Fishbein, M.; Ajzen, I. Predicting and Changing Behavior: The Reasoned Action Approach; Taylor Francis: Oxfordshire, UK, 2015.

36. Kahan, D.M.; Peters, E.; Wittlin, M.; Slovic, P.; Ouellette, L.L.; Braman, D.; Mandel, G. The polarizing impact of science literacy and numeracy on perceived climate change risks. Nat. Clim. Chang. 2012, 2, 732. [CrossRef]

37. Bak, H.J. Education and public attitudes toward science: Implications for the "deficit model" of education and support for science and technology. Soc. Sci. Q. 2001, 82, 779-795. [CrossRef]

38. Fielding, K.S.; Russell, S.; Spinks, A.; Mankad, A. Determinants of household water conservation: The role of demographic, infrastructure, behavior, and psychosocial variables. Water Resour. Res. 2012, 48. [CrossRef] 
39. Fielding, K.S.; Spinks, A.; Russell, S.; McCrea, R.; Stewart, R.; Gardner, J. An experimental test of voluntary strategies to promote urban water demand management. J. Environ. Manag. 2013, 114, 343-351. [CrossRef]

40. Buhrmester, M.; Kwang, T.; Gosling, S.D. Amazon's Mechanical Turk: A new source of inexpensive, yet high-quality, data? Perspect. Psychol. Sci. 2011, 6, 3-5. [CrossRef] [PubMed]

41. Mao, A.; Parkes, D.C.; Procaccia, A.D.; Zhang, H. Human computation and multiagent systems: An algorithmic perspective. In Proceedings of the Twenty-Fifth AAAI Conference on Artificial Intelligence, San Francisco, CA, USA, 7-8 August 2011.

42. Mason, W.; Suri, S. Conducting behavioral research on Amazon's Mechanical Turk. Behav. Res. Methods 2012, 44, 1-23. [CrossRef] [PubMed]

43. Gaziano, C.; McGrath, K. Measuring the concept of credibility. J. Q. 1986, 63, 451-462. [CrossRef]

44. Lindeman, R.H.; Merenda, P.F.; Gold, R.Z. Introduction to Bivariate and Multivariate Analysis; Scott Foresman and Co.: London, UK, 1980.

45. Chevan, A.; Sutherland, M. Hierarchical partitioning. Am. Stat. 1991, 45, 90-96.

46. R Core Team. R: A Language and Environment for Statistical Computing. R Foundation for Statistical Computing, Vienna, Austria. Available online: URLhttps://www.R-project.org/ (accessed on 15 April 2019).

47. Perloff, R.M. The Dynamics of Persuasion: Communication and Attitudes in the 21st Century; Routledge: Oxfordshire, UK, 1993.

48. O'Keefe, D.J. Message properties, mediating states, and manipulation checks: Claims, evidence, and data analysis in experimental persuasive message effects research. Commun. Theory 2003, 13, 251-274. [CrossRef]

49. Callison, C. Do PR practitioners have a PR problem?: The effect of associating a source with public relations and client-negative news on audience perception of credibility. J. Public Relat. Res. 2001, 13, 219-234. [CrossRef]

50. Murphy, P.P. Austin, Texas, Could Run Out of Water if Residents Don't Curb Use. Available online: https: //www.cnn.com/2018/10/23/us/austin-water-shortage-flooding/index.html (accessed on 24 October 2018).

(C) 2019 by the authors. Licensee MDPI, Basel, Switzerland. This article is an open access article distributed under the terms and conditions of the Creative Commons Attribution (CC BY) license (http://creativecommons.org/licenses/by/4.0/). 